\title{
COMORBID DEPRESSION AND SUICIDE IDEATION IN PATIENTS WITH COMBAT-RELATED PTSD: THE ROLE OF TEMPERAMENT, CHARACTER, AND TRAIT IMPULSIVITY
}

\author{
Nenad Jakšić ${ }^{1}$, Branka Aukst Margetić ${ }^{1,2}$ \& Darko Marčinko ${ }^{2,3}$ \\ ${ }^{l}$ National Center for Psychotrauma, Department of Psychiatry, University Hospital Center Zagreb, Zagreb, Croatia \\ ${ }^{2}$ School of Medicine, University of Zagreb, Zagreb, Croatia \\ ${ }^{3}$ Department of Psychiatry, University Hospital Center Zagreb, Zagreb, Croatia
}

received: 3.11.2016;

revised: 27.1.2017;

accepted: 7.2.2017

\section{SUMMARY}

Background: War veterans with PTSD have a high chance of developing major depressive disorder (MDD) at some point, while they can also exhibit increased suicidal tendencies. The primary goal of this research was to investigate whether personality dimensions, including temperament, character, and trait impulsivity, were associated with comorbid MDD, as well as with suicidal ideation in psychiatric patients suffering from combat-related PTSD.

Subjects and methods: The sample consisted of 148 Croatian male war veterans (mean age 49.53 years) treated for PTSD at the National Center for Psychotrauma, Department of Psychiatry, University Hospital Center Zagreb. Fifty-one (34\%) of them met ICD10 diagnostic criteria for current or lifetime MDD, while 97 (66\%) were diagnosed with PTSD alone. All the participants were assessed with the M.I.N.I. diagnostic interview and they completed the following battery of self-report instruments: the Beck Depression Inventory-Second Edition (BDI-II), the Suicidal Behaviors Questionnaire-Revised (SBQ-R), the Temperament and Character Inventory-Revised (TCI-R), and the Barratt Impulsiveness Scale-11 (BIS-11).

Results: Comparisons between the two clinical groups showed that PTSD+MDD patients were more suicidal and differed with regard to temperament dimensions Harm Avoidance, Reward Dependence and Persistence, character dimension Self-Directedness, and trait impulsivity. In three multivariate regression analyses, it was revealed that character dimension Cooperativeness as well as trait impulsivity were unique predictors of suicidal ideation, while controlling for the influence of sociodemographics, length of treatment and comorbid depression.

Conclusions: Combat-related PTSD patients with comorbid depression exhibit increased suicide thoughts and different personality profiles in comparison with those suffering from PTSD alone. Character dimension Cooperativeness and trait impulsivity seem to be uniquely predictive of suicide ideation in this population. Elucidation of individual psychological factors that increase the risk of MDD and suicidal tendencies in war veterans with PTSD may facilitate more effective prevention and treatment methods.

Key words: PTSD - comorbid depression - temperament-personality-impulsivity - suicide - war veterans

\section{INTRODUCTION}

Experiencing severe combat related stress and trauma during the war period may lead to posttraumatic stress disorder (PTSD). Previous research has suggested a wide range between $5 \%$ and $20 \%$ prevalence rates of PTSD in various military populations (Kok et al. 2012, Hines et al. 2014), with most studies converging on approximately $15 \%$ in US military personnel (Gates et al. 2012). For example, after the Homeland War in Croatia, the number of persons diagnosed with warrelated PTSD was 32,000, with some studies reporting around $18 \%$ prevalence of PTSD among individuals affected by the Croatian war (Priebe et al. 2010), and up to $33 \%$ among ex-Yugoslavia war refugees (Bogic et al. 2012). In addition to the primary symptoms of PTSD, many persons with PTSD also suffer co-occurring addictions, anxiety disorders, personality disorders, and other mental health illnesses (McDevitt-Murphy et al. 2010, Goldstein et al. 2016). Major depressive disorder (MDD) is probably the most common comorbid condition, with almost half of war veterans with PTSD also having a diagnosis of MDD, based on a recent meta-analytic study (Rytwinski et al. 2013). Moreover, some experts believe the comorbidity between PTSD and MDD represents a distinct phenotype, possibly even a subtype of PTSD (see Shah et al. 2012, Flory \& Yehuda 2015), and there are suggestions of specific names for this possibly separate psychobiological condition - 'posttraumatic mood disorder' (PTMD) (Sher 2005,2009 ). This perspective is somewhat supported by the growing empirical evidence that patients suffering from comorbid PTSD and MDD differ clinically and biologically from those suffering from PTSD or MDD alone, such as having greater severity of symptoms, higher social and occupational impairment, and more pronounced neurocognitive deficits (see Flory \& Yehuda 2015). A recent 4-year longitudinal study has found a particular combination of personality dimensions assessed at baseline, namely high Neuroticism and low Extraversion from the Big Five personality perspective, to be predictive of the subsequent development of comorbid PTSD and MDD, whereas they were not associated with new-onset cases of either disorder by 
itself (Spinhoven et al. 2014). Although such preliminary evidence points to unique individual vulnerabilities to developing comorbid PTSD and MDD, more research into potential psychobiological markers, such as one's temperamental and characterological traits, is highly warranted.

In addition to developing other psychiatric disorders, such as MDD, veterans who screen positive for PTSD are four times as likely to report suicidal ideation as their peers without PTSD (Jakupcak et al. 2009). If a veteran experienced a co-occurring disorder in addition to PTSD (e.g., depression), their risk increased to 5.7 times more likely than non-PTSD peers (Jakupcak et al. 2009). Rates of lifetime and/or current suicidal ideation previously found in military personnel with PTSD were $33-46 \%$ (Guerra et al. 2011). This is especially troublesome as suicidal ideation is generally the strongest predictor of suicide attempts (Mann et al. 2008). Pompili et al. (2013) recently conducted a systematic review of 80 empirical studies and concluded that having a history of PTSD diagnosis is linked to significant morbidity and mortality, including increased risk for suicidal ideation, attempts, and completed suicides in war veterans. Moreover, these relations remain after adjusting for psychiatric comorbidity (e.g., MDD) (Ramsawh et al. 2014). In the case of Croatian Homeland war that ended in 1995, it is important to remember that symptoms of PTSD and higher risk for suicide among war veterans may persist for and occur many years after their deployment (Price et al. 2004, Lončar et al. 2014).

Current literature describes a broad range of predisposing factors for increased suicide risk among active and retired military personnel, e.g. genetic vulnerabilities, traumatic childhood experiences, levels of combat exposure, physical injury, post-deployment social support, and psychiatric comorbidity (see Jakovljevic et al. 2012a, Pompili et al. 2013). One of the potential predisposing/protective factors for the development and expression of PTSD, as well as for general suicidal tendencies, lies in one's personality profile (Brezo et al. 2006, Flood et al. 2010). Here, the Cloninger's psychobiological model of personality (Cloninger et al. 1993), comprised of 4 temperament (Novelty Seeking, Harm Avoidance, Reward Dependence, Persistence) and 3 character (Self-Directedness, Cooperativeness, Self-Transcendence) dimensions, is especially relevant because of its substantial genetic and neurobiological underpinnings implicated in suicide phenomena. In addition, trait impulsivity has been proposed as a stable marker for suicide risk due to its link with serotonin dysfunction (Courtet et al. 2011). Various researchers have demonstrated the roles of personality dimensions, particularly harm avoidance/neuroticism, extraversion, and impulsivity, in suicidal ideation and behaviors (Brezo et al. 2006, Courtet et al. 2011, Perroud et al. 2013). Unfortunately, very few of these studies were conducted with war vete- rans suffering from PTSD. For example, Soltaninejad et al. (2014) have examined specific personality traits among Iranian military personnel, showing that neuroticism increases suicide risk, whereas extraversion and conscientiousness were linked to a reduced risk of suicide. Similarly, Na et al. (2013) suggested an association between character dimension Cooperativeness and suicide attempts in a sample of Korean male soldiers, but these participants were neither screened for nor diagnosed with PTSD. Our previous work with Croatian war veterans (Jaksic et al. 2015a) has linked temperament trait Harm Avoidance and, to a lesser degree, character trait Self-Directedness with the elevated suicide risk. However, this preliminary study was conducted on a small sample without controlling for the influence of comorbid depression and without the use of psychiatric diagnostic interviews. More research with military populations is needed to uncover specific personality dimensions, given their role as potential endophenotypes in suicide ideation and behaviors (see Courtet et al. 2011), that could be used in the early identification of increased suicide risk in these vulnerable individuals.

Based on the abovementioned gaps in the current literature on PTSD, comorbid depression and suicide risk, the main aims of this study were: 1) to assess specific personality dimensions (temperament and character dimensions and trait impulsivity), that might differentiate between isolated PTSD and PTSD with current or lifetime comorbid depression (i.e., posttraumatic mood disorder); and 2) to investigate the independent relations of personality dimensions and comorbid depression with increased suicide ideation in Croatian war veterans suffering from PTSD.

\section{SUBJECTS AND METHODS}

\section{Subjects}

We have recruited 148 Caucasian male adults being treated as psychiatric outpatients at the National Center for Psychotrauma, Department of Psychiatry, University Hospital Center Zagreb. These patients were war veterans who actively participated in the Croatian Homeland War (1991-1995) and were all suffering from combatrelated PTSD. The study data were gathered during 2014 and 2015. For the research purposes, these patients were approached by their psychiatrist or clinical psychologist, and those who were willing to take part in this study were assessed via a diagnostic interview. In addition, they filled out a battery of self-report measures, while waiting for their appointments, after the appointments had ended, or at home. While 20 patients refused to participate, no differences in age and education level between these patients and those taking part in this study were observed.

The formal ICD-10 (WHO 1992) diagnosis of PTSD (F43.1) was determined with a structured clinical 
interview - Mini International Neuropsychiatric Interview, Version 5.0.0 (M.I.N.I.; Sheehan et al. 1998) by the attending psychiatrist or clinical psychologist. Comorbid psychiatric diagnoses were also determined using the M.I.N.I., with 51 (34\%) of the PTSD patients also meeting diagnostic criteria for current major depressive disorder (MDD) or having a lifetime diagnosis of MDD based on their medical records and thorough unstructured clinical interviews. Those suffering from an established neurological or organic mental disorder, substance or alcohol abuse, acute psychotic disorder and/or schizophrenia, and those with low comprehension skills were not included in this study. We also excluded war veterans who had a history of psychiatric treatment prior to the Croatian Domestic War. The research protocol was thoroughly explained to the patients, after which their written informed consent was obtained. This empirical study was officially approved by the Ethics Committee of the University Hospital Center Zagreb.

The mean age of the sample was 49.53 years ( $S D=6.951$ years), while the range was between 36 and 64 years. Regarding their educational status, 16 (11\%) participants had completed elementary school, 109 (73\%) had completed high-school and 23 (16\%) held a university degree. The sample comprised $110(74.3 \%)$ married participants, $18(12.2 \%)$ single participants, 17 $(11.5 \%)$ divorced participants, and $1(0.7 \%)$ widowed participant. The average length of psychiatric treatment was 6.41 years $(S D=6.701$ years), ranging between 0 and 20 years. The average number of psychiatric hospitalizations (in any of the Croatian mental health institutions) was $1.11(S D=1.316)$, while the lowest and highest number of hospitalizations were 0 and 5 , respectively.

\section{Instruments}

The Mini International Neuropsychiatric Interview, Version 5.0.0 (M.I.N.I.; Sheehan et al. 1998) is a short structured diagnostic interview, used for establishing the diagnosis of posttraumatic stress disorder (PTSD) and major depressive disorder (MDD) according to the ICD10 diagnostic criteria.

The Beck Depression Inventory-Second Edition (BDI-II; Beck et al. 1996) is a self-report measure used for the examination of the severity of depressive symptoms. It contains 21 items in the form of statements that describe these symptoms. For each item, respondents are offered 4 statements and are asked to select the statement that best describes their mood in the last 2 weeks. It is measured on a 4-point scale, with higher scores indicating greater severity of depressive symptoms and a maximum possible score of 63 . The BDI - II has been previously translated and validated in a Croatian clinical sample (Jakšić et al. 2014). In the present study, Cronbach's alpha coefficient was 0.94 .

The Suicidal Behaviors Questionnaire-Revised (SBQ-R) (Osman et al. 2001) is a self-report measure of
4 different dimension of suicidality: lifetime suicidality, suicidal ideation over the past 12 months, verbalized threat of suicide attempt, and self-reported likelihood of future suicidal behavior. The four items can be summed into a total suicidal risk score that ranges from 3 to 18 . For the purposes of this research, we used the item assessing suicidal ideation over the past 12 months on a 5 -point scale (i.e., 1=never, $2=$ rarely, 3=sometimes, $4=$ often, and $5=$ very often). In this study, Cronbach's alpha coefficient for the entire scale was 0.83 .

The Temperament and Character Inventory-Revised (TCI-R) (Cloninger 1999) is a self-report instrument that assesses 4 temperament (Novelty seeking (NS), Harm Avoidance (HA), Reward Dependence (RD), and Persistence (PS)) and 3 character dimensions (SelfDirectedness (SD), Cooperativeness (CO), and SelfTranscendence (ST)) within the Cloninger's Psychobiological Model of Personality (Cloninger et al. 1993). It comprises 240 items rated on a 5-point Likert scale, ranging from 1 (definitely false) to 5 (definitely true). The Croatian adaptation of the TCI-R yielded adequate psychometric properties (internal consistencies, factorial and concurrent validity) in a large sample of psychiatric outpatients (Jaksic et al. 2015b). In the present study, Cronbach's alpha coefficients for the seven subscales ranged from 0.71 to 0.89 .

The Barratt Impulsiveness Scale-11 (BIS-11; Patton et al. 1995) is a self-report instrument developed to assess the personality/behavioral construct of impulsivity. It consists of 30 items that are scored on a 4-point scale from 1 (rarely/never) to 4 (almost always/always). The questionnaire contains three subscales (Attentional Impulsiveness, Motor Impulsiveness, and Nonplanning Impulsiveness) that can be summed into a global impulsiveness score. It is the most widely cited instrument for the assessment of impulsivity in the last 50 years (see Stanford et al. 2009). In the present study, Cronbach's alpha coefficient was 0.82 .

\section{Statistical Analysis}

We ran all the statistical analyses in the SPSS version 19 (SPSS, Chicago, IL). Descriptive statistics contained percentages, means (M) and standard deviations (SD). Internal reliabilities of the self-report measures were described by Cronbach's alpha coefficients. Independent samples t-test and chi-square test were used to examine the potential differences in sociodemographic and clinical variables, as well as personality dimensions between patients with isolated PTSD (PTSD group) and those with PTSD and current/lifetime MDD (PTSD + MDD group). The Bonferroni's adjustment was performed for multiple comparisons conducted with the t-test. Pearson correlations were computed to examine the zero-order relationship among the investigated variables. Finally, three multivariate regression analyses were performed to examine whether temperament dimensions, character dimensions, and trait impulsivity were 
independent predictors of suicidal ideation. In order to control for the influence of age, education level, length of psychiatric treatment, and comorbid depression, these variables were entered in the same block together with the personality factors. The initial level of statistical significance was set at $\mathrm{P}<0.05$.

\section{RESULTS}

In the overall sample, the mean value of depressive symptoms (i.e., BDI-2 total score, theoretical range 063) was $23.98(\mathrm{SD}=14.193)$, and the mean score of suicidal ideation (i.e., SBQ-R item 2, theoretical range 1-5) was 2.01 ( $\mathrm{SD}=1.209)$. The distribution of individual responses on the suicidal ideation scale was the following: $1 /$ never $(69 ; 47 \%)$, 2/rarely $(36 ; 25 \%)$, $3 /$ sometimes $(22 ; 15 \%), 4 /$ often $(10 ; 7 \%)$, and $5 /$ very often $(9 ; 6 \%)$.

Means and standard deviations of temperament and character scales were: NS 95.69 (13.698); HA 114.91 (23.252); RD 95.14 (16.693); PS 106.12 (26.009) SD 129.74 (20.580); C 128.0 (18.788); ST 73.65 (16.025). The average score on the measure of trait impulsivity (i.e., BIS-11 total score, theoretical range 30-120) was $66.84(\mathrm{SD}=10.541)$.

Table 1 presents the comparisons between the PTSD and PTSD+MDD groups of patients, with regard to the investigated sociodemographic, clinical, and personality factors. The level of statistical significance was appropriately reduced based on the Bonferroni's correction for multiple comparisons. We can see that none of the sociodemographic and treatment utilization variables differ between the two patient groups. The PTSD+MDD patients exhibited significantly higher scores on the selfreport measures of depressive symptoms and suicidal ideation. Within the psychobiological model of personality, the PTSD+MDD group had more pronounced temperament dimension Harm Avoidance, whereas less pronounced temperament dimensions Reward Dependence and Persistence, and character dimension SelfDirectedness. Trait impulsivity was significantly higher among the PTSD+MDD group in comparison to PTSD alone.

In Table 2 we presented the zero-order correlations between personality traits (temperament and character dimensions, and trait impulsivity) and sociodemographic and clinical variables. Here, the examined relations revealed that temperament trait Harm Avoidance, character traits Self-Directedness and Cooperativeness, and trait impulsivity had significant moderate-size correlations with suicidal ideation. Additionally, these traits, as well as Reward Dependence and Persistence, exhibited moderate or high correlations with the severity of depressive symptoms.

Finally, we assessed whether personality dimensions were predictors of self-reported suicidal ideation. Three multivariate regression analyses with suicidal ideation as a dependent variable and temperament dimensions, character dimensions, and trait impulsivity, respectively, as predictor variables, were performed. Age, education level, length of treatment, and comorbid depression were controlled for (Table 3 ). The first regression analysis

Table 1. Comparisons between the PTSD and PTSD+MDD groups in the investigated sociodemographic, clinical, and psychological variables

\begin{tabular}{|c|c|c|c|c|}
\hline & \multicolumn{2}{|c|}{ Mean (SD) } & \multirow{2}{*}{$\begin{array}{l}\text { t-test/ } \\
\chi^{2} \text { test }\end{array}$} & \multirow[b]{2}{*}{$\mathrm{P}$} \\
\hline & $\begin{array}{l}\text { PTSD } \\
(n=97)\end{array}$ & $\begin{array}{l}\text { PTSD + MDD } \\
\quad(n=51)\end{array}$ & & \\
\hline Age (years) & $47.88(7.273)$ & $49.90(6.252)$ & -1.676 & 0.096 \\
\hline Education level & - & - & 1.224 & 0.251 \\
\hline Lenght of treatment (months) & $71.22(81.556)$ & $89.85(78.501)$ & -1.290 & 0.199 \\
\hline Psychiatric hospitalizations & $1.06(1.368)$ & $0.88(1.248)$ & 0.762 & 0.447 \\
\hline BDI-2 total score & $15.52(8.033)$ & $39.74(8.570)$ & -16.968 & 0.000 \\
\hline SBQ-R suicidal ideation & $1.71(1.030)$ & $2.55(1.331)$ & -4.250 & 0.000 \\
\hline \multicolumn{5}{|l|}{ Temperament dimensions } \\
\hline Novelty Seeking & $96.12(13.410)$ & $94.00(13.803)$ & 0.894 & 0.373 \\
\hline Harm Avoidance & $105.14(19.345)$ & $132.20(18.994)$ & -8.057 & 0.000 \\
\hline Reward Dependence & $97.99(15.673)$ & $89.64(17.674)$ & 2.916 & 0.004 \\
\hline Persistence & $114.44(19.586)$ & $91.84(29.631)$ & 5.501 & 0.000 \\
\hline \multicolumn{5}{|l|}{ Character dimensions } \\
\hline Self-Directedness & $137.34(18.709)$ & $115.70(16.540)$ & 6.882 & 0.000 \\
\hline Cooperativeness & $131.25(18.104)$ & $122.46(18.993)$ & 2.733 & 0.007 \\
\hline Self-Transcendence & $71.73(15.664)$ & $76.36(16.048)$ & -1.679 & 0.095 \\
\hline Trait impulsivity & $63.61(10.11)$ & $72.86(8.556)$ & -5.555 & 0.000 \\
\hline
\end{tabular}

BDI-2 = Beck Depression Inventory $-2^{\text {nd }}$ Edition; SBQ-R suicidal ideation = Suicidal Behaviors Questionnaire-Revised;

Bonferroni's adjustment for multiple comparisons reduced the significance level to $\mathrm{P}=0.004$;

Significant $\mathrm{P}$ values are highlighted in italic 
Table 2. Pearson correlations between personality traits (temperament and character dimensions, trait impulsivity) and sociodemographic and clinical variables $(\mathrm{N}=148)$

\begin{tabular}{lccllllll}
\hline & NS & HA & RD & PS & SD & CO & ST & Impulsivity \\
\hline Age & $-0.27^{* *}$ & -0.12 & -0.03 & -0.03 & 0.20 & 0.01 & -0.06 & -0.09 \\
Education level & 0.08 & $-0.25^{* *}$ & $0.23^{* *}$ & $0.29 * *$ & $0.29^{* *}$ & $0.19^{*}$ & -0.01 & $-0.20^{*}$ \\
Length of treatment & 0.06 & 0.19 & -0.17 & -0.05 & -0.08 & -0.15 & 0.09 & $0.19^{*}$ \\
Psychiatric hospitalizations & 0.08 & 0.09 & $-0.29 * *$ & -0.12 & -0.01 & $-0.19^{*}$ & 0.09 & 0.06 \\
BDI-2 total score & 0.04 & $0.68^{* *}$ & $-0.33^{* *}$ & $-0.51^{* *}$ & $-0.61^{* *}$ & $-0.35^{* *}$ & $0.19^{*}$ & $0.58^{* *}$ \\
SBQ-R suicidal ideation & 0.08 & $0.31^{* *}$ & $-0.21^{*}$ & $-0.26^{* *}$ & $-0.31^{* *}$ & $-0.30^{* *}$ & 0.10 & $0.41^{* *}$ \\
\hline
\end{tabular}

$\mathrm{NS}=$ Novelty Seeking; HA= Harm Avoidance; RD= Reward Dependence; PS= Persistence; $\mathrm{SD}=$ Self-Directedness;

$\mathrm{CO}=$ Cooperativeness; ST= Self-Transcendence; BDI-2= Beck Depression Inventory $-2^{\text {nd }}$ Edition;

$\mathrm{SBQ}-\mathrm{R}=$ Suicidal Behaviors Questionnaire-Revised. Correlation coefficients $\geq 0.30$ are highlighted in italic. ${ }^{*} p<0.05$. ${ }^{* *} p<0.01$.

Table 3. Three multivariate regression analyses in predicting suicide ideation with temperament dimensions (Regression 1), character dimensions (Regression 2), and trait impulsivity (Regression 3), each adjusted for age, education level, length of treatment and comorbid depression $(\mathrm{N}=148)$

\begin{tabular}{|c|c|c|c|c|c|}
\hline & $\mathrm{R}$ & Sig. F Change & Standardized Beta & t-test & $\mathrm{P}$ \\
\hline Regression 1 & 0.375 & 0.012 & & & \\
\hline Age & & & -0.003 & -0.037 & 0.971 \\
\hline Education level & & & -0.003 & -0.029 & 0.977 \\
\hline Length of treatment & & & 0.013 & 0.151 & 0.880 \\
\hline Comorbid depression & & & 0.215 & 2.027 & 0.044 \\
\hline Novelty Seeking & & & 0.059 & 0.673 & 0.502 \\
\hline Harm Avoidance & & & 0.152 & 1.155 & 0.250 \\
\hline Reward Dependence & & & -0.107 & -1.126 & 0.262 \\
\hline Persistence & & & 0.005 & 0.040 & 0.968 \\
\hline Regression 2 & 0.416 & 0.001 & & & \\
\hline Age & & & 0.016 & 0.186 & 0.853 \\
\hline Education level & & & 0.007 & 0.079 & 0.937 \\
\hline Length of treatment & & & 0.017 & 0.206 & 0.837 \\
\hline Comorbid depression & & & 0.201 & 2.053 & 0.042 \\
\hline Self-Directedness & & & -0.129 & -1.141 & 0.256 \\
\hline Cooperativeness & & & -0.194 & -2.078 & 0.040 \\
\hline Self-Transcendence & & & 0.082 & 0.973 & 0.333 \\
\hline Regression 3 & 0.463 & 0.000 & & & \\
\hline Age & & & 0.006 & 0.073 & 0.942 \\
\hline Education level & & & -0.001 & -0.017 & 0.986 \\
\hline Length of treatment & & & 0.000 & -0.005 & 0.996 \\
\hline Comorbid depression & & & 0.179 & 1.998 & 0.048 \\
\hline Trait impulsivity & & & 0.354 & 3.950 & 0.000 \\
\hline
\end{tabular}

Significant $\mathrm{P}$ values are highlighted in italic

revealed a significant overall model, with comorbid depression as a significant predictor of suicidal ideation, whereas none of the temperament dimensions exhibited unique contribution to this prediction model. In the second regression analysis, in addition to comorbid depression, character dimension Cooperativeness was also a unique predictor of suicidal ideation. Lastly, the third regression analyses confirmed trait impulsivity, together with comorbid depression, to be significantly associated with suicidal ideation.

\section{DISCUSSION}

The primary goal of the current study was to investigate the role of personality dimensions, including temperament, character, and trait impulsivity, with regard to the occurrence of major depressive disorder (MDD) as well as suicidal ideation in Croatian war veterans suffering from combat-related PTSD.

Thirty-four (34\%) percent of PTSD patients in this study also had lifetime or current MDD, in line with other research showing high comorbidity between these two disorders, particularly among military and interpersonal trauma samples (see Rytwinski et al. 2013). Our findings have shown that none of the assessed sociodemographic (i.e., age, education level) and treatment utilization (i.e., length of treatment, number of psychiatric hospitalizations) variables differed between the two clinical groups - patients with PTSD and those with PTSD and comorbid MDD. However, the latter group was marked by higher levels of suicide ideation over the past 12 months, a finding consistent with 
previous research in this population (see Sher et al. 2012). In addition, significant differences in personality dimensions, even after adjusting the statistical risk level due to multiple comparisons, were obtained. Within the framework of Cloninger's psychobiological model of personality, the PTSD+MDD group had more pronounced temperament dimension Harm Avoidance (HA), whereas temperament dimensions Reward Dependence (RD) and Persistence (P) and character dimension Self-Directedness (SD) were lower than in the group of PTSD patients with no comorbid MDD. This would suggest that war veterans who also develop MDD in addition to PTSD are temperamentally more fearful, pessimistic and prone to anxiety under frustrating conditions (i.e., high in HA), socially detached, aloof and critical (i.e., lower in RD), less perservering, apathetic and underachieving (i.e., lower in PS), as well as lacking in purpose, resourcefulness, mature responsibility and self-acceptance (i.e., lower in SD) (Cloninger 2003). To the best of our knowledge, this was the first study to directly compare these two groups of PTSD patients using the Cloninger's temperament and character dimensions. Nevertheless, Spinhoven et al. (2014) conducted a longitudinal study in a large and clinically heterogeneous adult sample within the Big Five personality perspective. Namely, high Neuroticism (a personality trait similar to HA) and low Extraversion were predictive of the subsequent development of comorbid PTSD and MDD, whereas they were not associated with new-onset cases of either disorder by itself. Additionally, several studies that used cluster analysis or latent class analysis to identify subtypes of PTSD based on personality inventories suggested three distinct personality-based subtypes: internalizing, externalizing and 'simple' PTSD (e.g., Flood et al. 2010, Wolf et al. 2012). Internalizers display problems in the areas of depression, anxiety, social avoidance, they exhibit features of schizoid personality disorder, and are defined by two broad personality dimensions - high negative emotionality/neuroticism and low positive emotionality/extraversion. Interestingly, low temperament trait $\mathrm{RD}$ and character trait $\mathrm{SD}$, found to be less pronounced in the PTSD + MDD group of war veterans, are also characteristic of schizoid personality disorder from the perspective of the psychobiological model of personality (Svrakic \& Cloninger 2012). Finally, we also found significantly higher levels of self-reported trait impulsivity in the PTSD+MDD group, a personality dimension more often associated with externalizing types of PTSD (i.e., antisocial behaviors, aggression, substance abuse). Overall, the findings obtained in our study add to the existing literature that suggests PTSD and depression comorbidity is often associated with greater levels of distress, symptomatology, social impairment, and occupational and global disability when compared with those who have been diagnosed with PTSD alone (see Sher 2009, Jakovljevic et al. 2012b, Flory \& Yehuda 2015). Future research should investigate whether personality dimensions are in part responsible for some of the negative aspects of PTSD and MDD comorbidity, such as greater social impairment and occupational disability, irrespective of the intensity of depressive symptoms.

Our study demonstrated moderate zero-order correlations of $\mathrm{HA}, \mathrm{SD}$, Cooperativeness $(\mathrm{CO})$ and trait impulsivity with self-reported suicidal thoughts over the past 12 months in a sample of war veterans with PTSD. However, the two multivariate regression analyses showed that the effects of HA and SD were insignificant when all the temperament and character dimensions were examined simultaneously, while controlling for the influence of sociodemographic and clinical variables, including comorbid depression. In both these regressions, comorbid depression remained significantly associated with suicide ideation. Having in mind high correlations between $\mathrm{HA}, \mathrm{SD}$ and depressive symptoms obtained in this study, it seems the role of these two personality dimensions in suicidal phenomena among PTSD patients is largely exerted through the effects of depressive pathology. This is in line with previous research suggesting strong relations between HA and SD and depression in various clinical samples (see Mochcovitch et al. 2012). Moreover, two large longitudinal studies carried out in samples of participants from the general population demonstrated that high HA and low SD represent a prospective risk for the occurrence of future dysphoric and depressive episodes (Josefsson et al. 2011, Rosenstrom et al. 2014). Although several studies in different psychiatric populations indicated a link between at least one of these two personality dimensions and increased suicide risk (e.g., Aukst Margetic et al. 2012, Pawlak et al. 2013), future researches are encouraged to control for the influence of depressive symptoms when examining unique contributions of temperament and character to suicide ideation.

Character dimension $\mathrm{CO}$ was found to be significantly and uniquely associated with war veterans' suicide ideation over the last 12 months, and this effect was independent of other character dimensions as well as comorbid depression. It is suggested that war veterans with PTSD who fail to see themselves as an integral part of society and are lacking in interpersonal connectedness, compassion and empathy (i.e., low in $\mathrm{CO}$ ), are more prone to thoughts about ending their lives. This finding is in line with the results of another recent crosssectional study with military personnel diagnosed with adjustment disorder, but not PTSD, where low CO increased the risk of previous suicide attempts ( $\mathrm{Na}$ et al. 2013). On a related note, the Interpersonal-Psychological Theory of Suicide (Selby et al. 2010) describes the suicidal process as being characterized by subjective feelings and thoughts that one does not belong with other people, ideas that one presents a burden to others or society as a whole, and an acquired capability to overcome the fear of pain associated with suicide. Indeed, Bryan (2011) has showed that specific inter- 
personal factors, such as perceived burdensomeness and thwarted desire to belong, are major factors in promoting suicidal behaviors in military personnel. Given that character dimension $\mathrm{CO}$ is not strongly inherited and biologically predetermined personality trait (unlike temperament dimensions such as HA) (Cloninger 2003), our findings imply that interpersonally oriented psychotherapeutic methods and techniques focused on building and improving communicational and social skills (Markowitz \& Weissman 2004) might reduce suicide risk in combat-related PTSD populations. Finally, we demonstrated increased trait impulsivity to be also significantly associated with suicide ideation after controlling for various factors, including comorbid depression. Kotler et al. (2001) have also found such an association in a sample of patients suffering from PTSD, although they did not control for the influence of current depressive symptoms or disorder. In the existing literature on suicide phenomena, impulsive aggression and related disadvantageous decision making are conceptualized as endophenotypes for suicidal behaviors that reflect an underlying serotoninergic dysfunction (Courtet et al. 2011). Even though we did not screen for personality disorders in our study sample, high impulsivity is a common characteristic of individuals with cluster B personality disorders who are particularly prone to suicide ideation and attempts (Rihmer \& Benazzi 2010).

Some methodological limitations should be taken into consideration when discussing the findings of this study. The main limitation is the cross-sectional design, where only association, and not causation, can be demonstrated. However, several empirical studies have documented robust prospective associations between various personality dimensions and suicide tendencies in psychiatric populations. Future longitudinal studies should investigate potential mediating and moderating factors (e.g., levels of combat exposure, post-deployment social support, dissociative phenomena, genetic and neurobiological influences) of the personalitysuicide relationships. Some authors have stressed out the need for more thorough examination of post-war social and political circumstances where veterans' feelings of disappointment, frustration and injustice, sometimes referred to as posttraumatic embitterment syndrome (see Linden et al. 2008, Jakovljevic et al. 2012b), can promote and exacerbate symptoms of PTSD and suicidal tendencies. Our research team is currently interpreting statistical data and preparing potential publications about posttraumatic embitterment and its psychological and genetic correlates in Croatian war veterans, all of which was obtained within the broader international project titled "Molecular mechanisms of PTSD" (Dzubur-Kulenovic et al. 2016). In addition, patients with(out) lifetime MDD were allocated to one of the two groups based on their medical records and clinical interviews. Even though structured diagnostic measures (e.g., SCID-I) assessing lifetime MDD would probably be more rigorous, prior research has indicated good overlap between SCID-I, medical records and selfreported history of depression (Stuart et al. 2014, Sanchez-Villegas et al. 2008). Interview methods for the assessment of suicide ideation were not performed, however, there is evidence that self-report measures of suicidality can sometimes provide greater validity than interview methods, especially when examining recent suicide thoughts (Kaplan et al. 1994). Finally, additional aspects of suicidality (e.g., number of suicide attempts, suicide methods and lethality) should be explored in future studies with war veterans suffering from PTSD.

\section{CONCLUSIONS}

War veterans with combat-related PTSD and comorbid depressive disorder seem to be more suicidal and characterized by different personality profile than those suffering from PTSD alone. Character dimension Cooperativeness and trait impulsivity were uniquely predictive of suicide ideation in this population, even after controlling for the influence of comorbid depression. Identification of individual psychological factors that promote the occurrence of MDD and suicidal tendencies in war veterans with PTSD may facilitate more effective prevention and treatment methods. Additional pre- and post-deployment risk factors should also be investigated, particularly in studies with longitudinal research designs.

\section{Acknowledgements: None.}

\section{Conflict of interest: None to declare.}

\section{Contribution of individual authors:}

Nenad Jakšić: design of the study, data collection, literature searches, statistical analyses, interpretation of results, writing the first draft, revising the manuscript, approval of the final version.

Branka Aukst Margetić: design of the study, data collection, literature searches, interpretation of results, comments on the first draft, revising the manuscript, approval of the final version.

Darko Marčinko: design of the study, interpretation of results, comments on the first draft, revising the manuscript, approval of the final version.

\section{References}

1. Aukst Margetic B, Jakovljevic M, Ivanec D, Marcinko D, Margetic B, Jaksic N: Current suicidality and previous suicidal attempts in patients with schizophrenia are associated with different dimensions of temperament and character. Psychiatry Res 2012; 200:120-5.

2. Beck AT, Steer RA, Brown GK: Manual for the Beck Depression Inventory-II. Psychological Corporation, San Antonio, 1996. 
3. Bogic M, Ajdukovic D, Bremner $S$, Franciskovic $T$, Galeazzi GM, Kucukalic A, Priebe S: Factors associated with mental disorders in long-settled war refugees: refugees from the former Yugoslavia in Germany, Italy and the UK. British Journal of Psychiatry 2012; 200:216-23.

4. Brezo J, Paris J, Turecki G: Personality traits as correlates of suicidal ideation, suicide attempts, and suicide completions: a systematic review. Acta Psychiatr Scand 2006; 113:180-206.

5. Bryan CJ: The clinical utility of a brief measure of perceived burdensome- ness and thwarted belongingness for the detection of suicidal military personnel. Journal of Clinical Psychology 2011; 67:981-992.

6. Cloninger CR: The Temperament and Character Inventory - Revised (TCI-R). Center for Psychobiology of Personality, Washington University, St. Louis, Missouri, 1999.

7. Cloninger CR: Completing the psychobiological architecture of human personality development: Temperament, character, and coherence. In Staudinger $U$, Lindenberger $U$ (eds.): Understanding human development: Dialogues with lifespan psychology, 159-181. Kluwer, Boston, MA, 2003.

8. Cloninger CR, Svrakic DM, Przybeck TR: A psychobiological model of temperament and character. Arch Gen Psychiatry 1993; 50:975-90.

9. Courtet P, Gottesman II, Jollant F, Gould TD: The neuroscience of suicidal behaviors: what can we expect from endophenotype strategies? Transl Psychiatry 2011; 1:e7.

10. Dzubur-Kulenovic A, Agani F, Avdibegovic E, Jakovljevic M, Babic D, Kucukalic A, et al.: Molecular Mechanisms of Posttraumatic Stress Disorder (PTSD) as a Basis for Individualized and Personalized Therapy: Rationale, Design and Methods of the South Eastern Europe (SEE)PTSD study. Psychiatr Danub 2016; 28:154-63.

11. Flood AM, Boyle SH, Calhoun PS, Dennis MF, Barefoot JC, Moore SD, et al.: Prospective study of externalizing and internalizing subtypes of posttraumatic stress disorder and their relationship to mortality among Vietnam veterans. Compr Psychiatry 2010; 51:236-242.

12. Flory JD, Yehuda R: Comorbidity between post-traumatic stress disorder and major depressive disorder: alternative explanations and treatment considerations. Dialogues Clin Neurosci 2015; 17:141-150.

13. Gates MA, Holowka DW, Vasterling JJ, Keane TM, Marx $B P$, Rosen RC: Posttraumatic stress disorder in veterans and military personnel: epidemiology, screening, and case recognition. Psychological Services 2012; 9:361-82.

14. Goldstein RB, Smith SM, Chou SP, Saha TD, Jung J, Zhang H, Grant BF: The epidemiology of DSM-5 posttraumatic stress disorder in the United States: results from the National Epidemiologic Survey on Alcohol and Related Conditions-III. Social Psychiatry and Psychiatric Epidemiology 2016; 51:1137-48.

15. Guerra VS, Calhoun PS; Mid-Atlantic Mental Illness Research, Education and Clinical Center Workgroup: Examining the relation between posttraumatic stress disorder and suicidal ideation in an OEF/OIF veteran sample. J Anxiety Disord 2011; 25:12-8.

16. Hines LA, Sundin J, Rona RJ, Wessely S, Fear NT: Posttraumatic Stress Disorder Post Iraq and Afghanistan: Prevalence Among Military Subgroups. Can J Psychiatry 2014; 59:468-479.

17. Jakovljevic M, Brajkovic L, Jaksic N, Loncar M, AukstMargetic B, Lasic D: Posttraumatic stress disorder
(PTSD) from different perspectives: a transdisciplinary integrative approach. Psychiatr Danub 2012a; 24:24655 .

18. Jakovljević $M$, Brajković L, Lončar $M \&$ Čima A: Posttraumatic stress disorder between fallacy and facts: What we know and what we don't know? Psychiat Danub 2012b; 24:241-45.

19. Jakšić N, Aukst-Margetić B, Marčinko D, Brajković L, Lončar M, Jakovljević M: Temperament, character, and suicidality among Croatian war veterans with posttraumatic stress disorder. Psychiatr Danub 2015a; 27:60-3.

20. Jaksic N, Aukst-Margetic B, Rozsa S, Brajkovic L, Jovanovic N, Vuksan-Cusa B, Grubisin J, Kudlek-Mikulic S, Jevtovic S, Marcinko D, Svrakic DM, Jakovljevic M: Psychometric properties and factor structure of the Temperament and Character Inventory-Revised (TCI-R) in a Croatian psychiatric outpatient sample. Compr Psychiatry 2015b; 57:177-86.

21. Jakšić N, Ivezić E, Jokić-Begić N, Suranyi Z, StojanovićŠpehar S: Factorial and diagnostic validity of the Beck Depression Inventory - II (BDI-II) In Croatian primary health care. J Clin Psychol Med Settings 2013; 20:311-22.

22. Jakupcak M, Cook J, Imel Z, Fontana A, Rosenheck R, McFall M: Posttraumatic stress disorder as a risk factor for suicidal ideation in iraq and afghansitan war veteran. Journal of Traumatic Stress 2009; 22:303-306.

23. Josefsson K, Merjonen P, Jokela M, Pulkki-Råback L, Keltikangas-Järvinen L: Personality profiles identify depressive symptoms over ten years? A population-based study. Depress Res Treat 2011; 11:1-11.

24. Kaplan ML, Asnis GM, Sanderson WC, Keswani L, De Lecuona JM, Joseph S: Suicide assessment: clinical interview vs. self-report. J Clin Psychol 1994; 50:294-298.

25. Kok BC, Herrell RK, Thomas JL, Hoge CW: Posttraumatic stress disorder associated with combat service in Iraq or Afghanistan: reconciling prevalence differences between studies. J Nerv Ment Dis 2012; 200:444-50.

26. Kotler M, Iancu I, Efroni R, Amir M: Anger, impulsivity, social support, and suicide risk in patients with posttraumatic stress disorder. J Nerv Ment Dis 2001; 189:162-7.

27. Linden M: Posttraumatic embitterment disorder and wisdom therapy. Journal of Cognitive Psychotherapy: An International Quarterly 2008; 22:4-14.

28. Lončar M, Plašć ID, Bunjevac T, Hrabač P, Jakšić N, Kozina S, Henigsberg $N$, Šagud M, Marčinko D: Predicting symptom clusters of posttraumatic stress disorder (PTSD) in Croatian war veterans: the role of socio-demographics, war experiences and subjective quality of life. Psychiatr Danub 2014; 26:231-8.

29. Mann JJ, Ellis SP, Waternaux CM, Liu X, Oquendo MA, Malone KM, et al.: Classification trees distinguishing suicide attempters in major psychiatric disorders: A model of clinical decision making. Journal of Clinical Psychiatry 2008; 69:23-31.

30. Markowitz JC, Weissman MM: Interpersonal psychotherapy: principles and applications. World Psychiatry 2004; 3:136-139.

31. McDevitt-Murphy ME, Williams JL, Bracken KL, Fields JA, Monahan CJ, Murphy JG: PTSD Symptoms, Hazardous Drinking, and Health Functioning among U.S.OEF/OIF Veterans Presenting to Primary Care. Journal of Traumatic Stress 2010; 23:108-111. 
32. Mochcovitch MD, Nardi AE, Cardoso A: Temperament and character dimensions and their relationship to major depression and panic disorder. Rev Bras Psiquiatr 2012; 34:342-51.

33. Na KS, Oh SJ, Jung HY: Alexithymia and low cooperativeness are associated with suicide attempts in male military personnel with adjustment disorder: a case-control study. Psychiatry Res 2013; 205:220-6.

34. Osman A, Bagge CL, Guitierrez PM, Konick LC, Kooper BA, Barrios FX: The Suicidal Behaviors QuestionnaireRevised (SBQ-R): validation with clinical and nonclinical samples. Assess 2001; 5:443-54.

35. Patton JH, Stanford MS, Barratt ES: Factor structure of the Barratt Impulsiveness Scale. J Clin Psychol 1995; 51:768-74.

36. Pawlak J, Dmitrzak-Węglarz M, Skibińska M, et al.: Suicide attempts and psychological risk factors in patients with bipolar and unipolar affective disorder. Gen Hosp Psychiatry 2013; 35:309-313.

37. Perroud N, Baud P, Ardu S, Krejci I, Mouthon D, Vessaz M, et al.: Temperament personality profiles in suicidal behaviour: An investigation of associated demographic, clinical and genetic factors. J Affect Disord 2013; 146:246-253.

38. Pompili M, Sher L, Serafini G, Forte A, Innamorati M, Dominici G, Lester D, Amore M, Girardi P: Posttraumatic stress disorder and suicide risk among veterans: a literature review. J Nerv Ment Dis 2013; 201:802-12.

39. Price RK, Risk NK, Haden AH, Lewis CE, Spitznagel EL: Post-traumatic stress disorder, drug dependence, and suicidality among male Vietnam veterans with a history of heavy drug use. Drug Alcohol Depend 2004; 76:S31-43.

40. Priebe S, Bogic M, Ajdukovic D, Franciskovic T, Galeazzi GM, Kucukalic A, Schuetzwohl M: Mental disorders following war in the Balkans: a study in 5 countries. Archives of General Psychiatry 2010; 67:518-28.

41. Ramsawh HJ, Fullerton CS, Mash HB, Ng TH, Kessler $R C$, Stein MB, Ursano RJ: Risk for suicidal behaviors associated with PTSD, depression, and their comorbidity in the U.S. Army. J Affect Disord 2014; 161:116-22.

42. Rihmer Z, Benazzi F: Impact on suicidality of the borderline personality traits impulsivity and affective instability. Ann Clin Psychiatry 2012; 22:121-128.

43. Rosenström T, Jylhä P, Cloninger CR, et al: Temperament and character traits predict future burden of depression. $J$ Affect Disord 2014; 158:139-47.

44. Rytwinski NK, Scur MD, Feeny NC, Youngstrom EA: The co-occurrence of major depressive disorder among individuals with posttraumatic stress disorder: a metaanalysis. J Trauma Stress 2013; 26:299-309.

45. Sanchez-Villegas A, Schlatter J, Ortuno F, Lahortiga F, Pla J, Benito S, Martinez-Gonzalez MA: Validity of a self- reported diagnosis of depression among participants in a cohort study using the Structured Clinical Interview for DSM-IV (SCID-I). BMC Psychiatry 2008; 8:43.

46. Selby EA, Anestis MD, Bender TW, et al.: Overcoming the fear of lethal injury: evaluating suicidal behavior in the military through the lens of the Interpersonal-Psychological Theory of Suicide. Clin Psychol Rev 2010; 30:298-307.

47. Shah R, Shah A, Links P: Post-traumatic stress disorder and depression comorbidity: severity across different populations. Neuropsychiatry 2012; 2:521-529

48. Sheehan DV, Lecrubier Y, Harnett-Sheehan K, Amorim P, Janavs J, Weiller E, Hergueta T, Baker R, Dunbar G: The Mini International Neuropsychiatric Interview (M.I.N.I.): The Development and Validation of a Structured Diagnostic Psychiatric Interview. J Clin Psychiatry 1998; 59(Suppl 20):22-33.

49. Sher L: The concept of post-traumatic mood disorder. Med Hypotheses 2005; 65:205-210.

50. Sher L: A model of suicidal behavior in war veterans with posttraumatic mood disorder. Med Hypotheses 2009; 73:215-9.

51. Sher L, Braquehais MD, Casas M: Posttraumatic stress disorder, depression, and suicide in veterans. Cleve Clin J Med 2012; 79:92-7.

52. Soltaninejad A, Fathi-Ashtiani A, Ahmadi K, Mirsharafoddini HS, Nikmorad A, Pilevarzadeh M: Personality factors underlying suicidal behavior among military youth. Iran Red Crescent Med J 2014; 16:e12686.

53. Spinhoven P, Penninx BW, van Hemert AM, de Rooij M, Elzinga BM: Comorbidity of PTSD in anxiety and depressive disorders: prevalence and shared risk factors. Child Abuse Negl 2014; 38:1320-1330.

54. Stanford MS, Mathias CW, Dougherty DM, Lake SL, Anderson NE, Patton JH: Fifty years of the Barratt Impulsiveness Scale: An update and review. Personality and Individual Differences 2009; 47:385-395.

55. Stuart AL, Pasco JA, Jacka FN, Brennan SL, Berk M, Williams LJ: Comparison of self-report and structured clinical interview in the identification of depression. Compr Psychiatry 2014; 55:866-9.

56. Svrakic DM, Cloninger CR: Pharmacotherapy and the Psychobiological Model of Personality: Implications for DSM-5. Current Psychopharmacology 2012; 1:122-136.

57. Wolf EJ, Miller MW, Harrington KM, Reardon A: Personality-based latent classes of posttraumatic psychopathology: personality disorders and the internalizing/ externalizing model. J Abnorm Psychol 2012; 121:256-62.

58. World Health Organization: International statistical classification of diseases and related health problems (10th rev.). WHO, Geneva, 1992.

Correspondence:

Nenad Jakšić, MPsych

National Center for Psychotrauma, Department of Psychiatry

University Hospital Center Zagreb

Kispatićeva 12, 10000 Zagreb, Croatia

E-mail:nenad_jaksic@yahoo.com 